\title{
Moving Pharmacy Benefits from Nice to Have to Essential Benefits
}

\author{
Kim A. Caldwell, RPh, and Babette Edgar, PharmD, FAMCP
}

$\mathrm{I}$ $\mathrm{t}$ is hard to believe that is has been over 20 years that we have been focused on prescriptions for the Medicare population. When the Balanced Budget Act of 1997 officially authorized Medicare+Choice plans-which had existed as demonstration projects since the early 1970s_Kim Caldwell was working for a large regional health plan in the

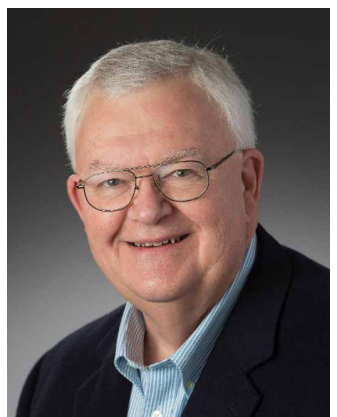
Southwest primarily focusing on the newly competitive senior population. During this period, the pharmacy benefit was an unfunded Medicare option offered by plans to be competitive in the marketplace. Kim's goal was to use medical and pharmacy data to identify the most at-risk senior patients, a lofty aim given that, at the time, medical and pharmacy data programs did not speak to each other nor could their data be joined. The research, outreach, and consultations were effectively an early version of today's medication therapy management (MTM). Meanwhile, in the early 2000s, Babette Edgar was working for a large pharmacy benefit manager, assisting with research and clinical programs to prepare for the impending Part D benefit.

Jump ahead to December 8, 2003. On that day, President George W. Bush signed the Medicare Prescription Drug, Improvement, and Modernization Act, commonly called the Medicare Modernization Act into law. This signature delivered the largest overhaul of Medicare in its (then) 38-year history. The act included the renaming of the Medicare+Choice program to Medicare Advantage, along with a set of drastic improvements to operations and offerings from these plans. Of most importance, however, was the creation of Medicare Part D, which is the section of the larger Medicare program's "entitlement benefits" that covers pharmaceutical products and services. This is where the plot thickens.

Implementation of the Medicare Modernization Act into reality was unusual in that there was an absolute "get it going by date," or the program's flexibility went away. Said differently,

\footnotetext{
J Manag Care Spec Pharm. 2020;26(8):943-44

Copyright $\odot 2020$, Academy of Managed Care Pharmacy. All rights reserved.
}

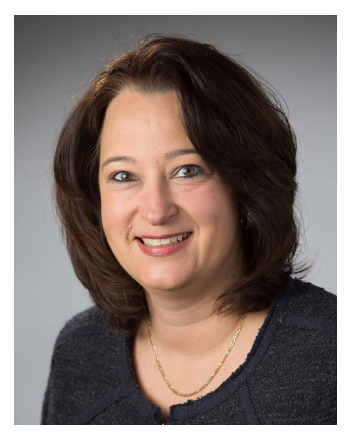

there were only 2 years and 23 days from signature until start date of January 1, 2006. Under the extremely skillful leadership of then Centers for Medicare \& Medicaid Services (CMS) Administrator Dr. Mark McClellan, CMS and other government staff worked aggressively to write and publish the proposed Program Rules on August 4, 2004. Comments were due by October 4, 2004. Without waiting until the final comments had been received and studied, Administrator McClellan made the decision that there must be 2 experienced, nongovernment managed care pharmacists hired to lead 2 of the 4 divisions charged with final rule writing, implementing, evaluating, and contracting of the initial Part D plans for calendar year 2006. We-Kim Caldwell and Babette Edgar-were the "lucky" ones coerced into joining this party. Fortunately, we had previously worked together at AdvancePCS. As friends and experienced colleagues, we were ready for the battle and began our employment as division directors within the Medicare Drug Benefit Group on October 17, 2004. One of our first and most critical duties was the hiring of key staff for our divisions, specifically, managed care pharmacists.

Before implementation, there were legitimate concerns that there would not be enough plans participating to make Part D successful. In fact, the act even included a mandate for a fallback plan as a safeguard. Instead, there was an overwhelming bid response from organizations. Many companies were experienced with providing pharmacy benefits, and others were attempting to learn as they moved forward. From the beginning, this benefit was extremely popular with beneficiaries; Part D delivered a surprising member satisfaction rate in the $85 \%$ range right out of the gate. Much of the benefit was not automated in 2006 , since only about $27 \%$ of members reported being "computer friendly." However, that has morphed over the years as beneficiaries became more tech-savvy, with online enrollment enhancements, online formularies, medication searches, and pharmacy finders. In addition, a formulary review process was developed that ensured appropriate access 
to a wide variety of medications consistent with best practice commercial formularies and also ensured that formularies were nondiscriminatory by including drugs for all disease states for which drugs existed. Plan formularies have evolved over time as tight formulary regulations have loosened a bit to allow plans to use managed care tools to drive down costs and ensure safe medication practices.

Drug adherence, which may lead to improved outcomes, has been a struggle from the managed care perspective, as well as from the patient perspective as they battle costs, transportation issues, adverse effects, and lack of education. CMS has supported our industry and its beneficiaries by requiring MTM programs and, more recently, by allowing the enhanced MTM programs a financial incentive for improved outcomes. Managed care organizations are able to use the tools that work to improve outcomes and drive down costs. In addition, CMS has implemented 3 specific quality measures in the Part D area of the star ratings specific to adherence of medications: Medication Adherence for Diabetes Medications, Hypertension (RAS antagonists), and Cholesterol (Statins). By offering financial incentives for plans, CMS is stressing the importance of adherence to medications in these critical and costly disease categories. Medicare is driving enhanced adherence through payment for success, which often is mimicked by other lines of business.

Medicare Part D plans have fully invested time, talent, resources, skills, and technology to improve the health and wellness of Medicare beneficiaries using managed care tools. As the Medicare program continues to mature, managed care pharmacy will always work with CMS to save money, increase access, and drive outcomes.

\section{Authors}

KIM A. CALDWELL, RPh, Principal, Texas Star Healthcare Consulting, McKinney, Texas, and BABETTE EDGAR, PharmD, FAMCP, Area Senior Vice President, BluePeak Advisors, a Division of Gallagher Benefits Services, Rolling Meadows, Illinois.

AUTHOR CORRESPONDENCE: Kim A. Caldwell, Texas Star Healthcare Consulting, 3329 Drip Rock Dr., McKinney, TX 75070. Tel.: 214.392.1096; Email: texascaldwell@yahoo.com.

\section{DISCLOSURES}

No funding supported the writing of this commentary. The authors have nothing to disclose. 